\title{
Komatiites as Mercury surface analogues: Spectral measurements at PEL
}

\author{
Alessandro Maturilli ${ }^{\mathrm{a}, *}$, Jörn Helbert ${ }^{\mathrm{a}}$, James M. St. John ${ }^{\mathrm{b}}$, James W. Head III ${ }^{\mathrm{c}}$, \\ William M. Vaughan ${ }^{c}$, Mario D’Amore ${ }^{\mathrm{a}}$, Matthias Gottschalk ${ }^{\mathrm{d}}$, Sabrina Ferrari ${ }^{\mathrm{a}}$ \\ a Institute for Planetary Research, German Aerospace Center DLR, Rutherfordstr. 2, Berlin-Adlershof, Germany \\ b School of Earth Sciences, The Ohio State University at Newark, Newark, OH 43055, USA \\ c Department of Geological Sciences, Brown University, Providence, RI 02912, USA \\ d Department of Chemistry and Physics of Earth Materials, Deutsches GeoForschungsZentrum GFZ, Potsdam, Germany
}

\section{A R T I C L E I N F O}

\section{Article history:}

Received 25 November 2013

Received in revised form 21 April 2014

Accepted 22 April 2014

Available online $\mathrm{xxxx}$

Editor: L. Stixrude

\section{Keywords:}

Mercury

spectroscopy

surface analogues

\begin{abstract}
A B S T R A C T
The elemental composition of Mercury's surface, which has been recently measured by the NASA MErcury Surface, Space ENvironment, GEochemistry, and Ranging (MESSENGER) spacecraft, suggests a mineralogy dominated by magnesium-rich orthopyroxene and feldspar. The most magnesium-rich and aluminium-poor regions of Mercury's surface (which are presumably orthopyroxene-rich) have compositions, and possibly mineralogies, analogous to terrestrial boninites and basaltic komatiites. Unfortunately, little is known about the spectral properties of komatiites, especially at the high surface temperatures of Mercury. We therefore have collected three terrestrial komatiites with different compositions plus a synthetic komatiitic sample, and measured their reflectances in the visible and thermal infrared spectral ranges. Samples divided into four grain size ranges (when enough material was available) were measured fresh and after thermal processing in vacuum $(10 \mathrm{~Pa})$ at $500^{\circ} \mathrm{C}$, comparable to Mercury peak surface temperatures. Our measurements show that spectral changes between fresh and thermally processed samples occur in both spectral channels, but are stronger in the visible range, with reddening affecting all the samples, while darkening is more selective. It is important to note that darkening and reddening after thermally processing the samples are independent of the komatiites ferrous iron content. In fact the synthetic sample which is nearly iron-free is most strongly affected. From our study it turns out that thermally processing the samples in vacuum at Mercury surface temperature produces the removal of samples' colour centres. The results of our study show also that the Mercury Atmospheric and Surface Composition Spectrometer (MASCS) instrument on MESSENGER orbiting Mercury currently cannot distinguish between different compositions of komatiites, while the future MErcury Radiometer and Thermal infrared Imaging Spectrometer (MERTIS) on the upcoming ESA BepiColombo mission will resolve their differences in the 7-14 $\mu \mathrm{m}$ spectral range.
\end{abstract}

(c) 2014 Elsevier B.V. All rights reserved.

\section{Introduction}

The chemistry of the surface of Mercury has been measured and mapped from orbit by X-ray and gamma-ray spectrometers on board the MErcury Surface, Space ENvironment, GEochemistry, and Ranging (MESSENGER) spacecraft (Nittler et al., 2011; Peplowski et al., 2011, 2012; Evans et al., 2012; Weider et al., 2012). These measurements demonstrate that the surface composition of Mercury differs from the other terrestrial planets: Mercury's high $\mathrm{Mg} / \mathrm{Si}$ and low $\mathrm{Al} / \mathrm{Si}$ and $\mathrm{Ca} / \mathrm{Si}$ exclude a feldspathic surface composition like

\footnotetext{
* Corresponding author.

E-mail address: alessandro.maturilli@dlr.de (A. Maturilli).
}

that of the lunar highlands, whereas high $\mathrm{Mg} / \mathrm{Si}$ and low $\mathrm{Fe} / \mathrm{Si}$ and $\mathrm{Ca} / \mathrm{Si}$ exclude a surface composition similar to terrestrial or lunar basalts (Nittler et al., 2011). Mercury's surface composition seems to be most similarly to the compositions of enstatite chondrite melts and certain enstatite achondrites (Nittler et al., 2011; Weider et al., 2012). The closest terrestrial magmas to these compositions are boninites and basaltic komatiites (Charlier et al., 2013). Derived chemical compositions have been used to determine the normative mineralogy of Mercury's surface (Stockstill-Cahill et al., 2012), which, like enstatite achondrites, seems to be dominated by magnesian orthopyroxene, sodium-rich plagioclase feldspar, and lesser amounts of $\mathrm{Ca}, \mathrm{Mg}$, and/or Fe sulfides. These analog materials have been already spectrally characterized at mercurian conditions in 
order to better understand the spectral properties of the mercurian surface (see, e.g., Maturilli et al., 2008; Helbert and Maturilli, 2009; Helbert et al., 2013a).

Yet these analogs alone do not completely capture the complexity and compositional variability of the mercurian surface: recent XRS analyses (Nittler et al., 2013) reveal that a large region of Mercury (constituting about $1 / 10$ th of the planet's surface) has an $\mathrm{Mg} / \mathrm{Si}$ ratio approaching 1 (much of the rest of the planet has $\mathrm{Mg} / \mathrm{Si} \sim 0.5$ or less). This region, also Ca- and $\mathrm{S}$-rich, is $\mathrm{Al}-$ poor. Accordingly, the mineralogy of this high-Mg region is likely dominated by magnesian orthopyroxene. While the igneous mineralogy of most komatiites is olivine and/or clinopyroxene dominated, there is one example (Commondale) whose mineralogy is dominated by orthopyroxene (Wilson, 2003) and so is our closest terrestrial analog for the high-Mg region on Mercury. Komatiite analog materials have generally not been spectrally characterized at mercurian conditions. Following the work we published on sulfides as analogs for Mercury hollows formation (Helbert et al., 2013a), in order to better understand the spectral properties of high-Mg regions on the mercurian surface, we have measured visible and thermal infrared spectra for a suite of komatiitic samples under a range of environmental conditions at the Planetary Emissivity Laboratory (PEL) at the German Aerospace Center (DLR), as a further step in our ongoing efforts of spectrally characterising a range of possible analogs for Mercury surface composition.

\section{Materials and methods}

\subsection{Komatiite samples}

Virtually all the terrestrial komatiites and komatiitic basalts are of Archean age, and the general consensus is that komatiites are produced by plumes, even though there are some komatiites, Commondale in particular, that are very difficult to fit into a plume scenario because their high $\mathrm{SiO}_{2}$ suggests relatively shallow melting, and a probable formation in presence of water (Wilson, 2003). Komatiites usually form the lower parts of the greenstones sequences they belong to, at the time of their formation the magmas were hot and dense, with very low viscosities, in respect to the typical values for liquid basalts (Nisbet, 1984).

For the study presented in this paper, we examined 3 natural komatiites, from Barberton (South Africa, 3.5 Ga old), Commondale (South Africa, 3.3 Ga old), and Belingwe (Zimbabwe, 2.7 Ga old), and a synthetic one produced at the Brown University Department of Geological Sciences.

The Barberton material is an olivine spinifex komatiite from the Paleoarchean-aged (3.481 Ga) Lower Komati Formation in the Komati River Valley area, South Africa. This is the type locality, known for the best-preserved very old komatiites on Earth. Unfortunately, the sample has been metamorphosed into black serpentinite, changing its mineralogy (Parman et al., 1997). We thus obtained samples of the remarkably fresh Belingwe komatiite described in the paper from Nisbet et al. (1987) and Shimizu et al. (2005), being another olivine spinifex komatiite which contains unaltered olivine and glass. Olivine spinifex komatiites such as Barberton and Belingwe contain nearly 10 wt.\% FeO, probably $>10$ times the concentration of FeO on Mercury's surface (Nittler et al., 2011). High FeO renders these komatiites suspect as a Mercury spectral analog; moreover, the high $(\mathrm{Fe}+\mathrm{Mg}) / \mathrm{Si}$ of these komatiites suggests an olivine-dominated mafic mineralogy, not the orthopyroxene-dominated mineralogy suggested for Mercury in the recent paper by Stockstill-Cahill et al. (2012). As a next step, we collected samples of the low-FeO ( $\sim$ wt.\% FeO), pyroxene-normative Commondale komatiite, whose peculiarities are described in the paper by Williams et al. (2000). Unfortunately, this komatiite has also undergone substantial alteration; for
Table 1

Comparison of major element composition for the 4 komatiite samples (in wt.\%).

\begin{tabular}{lcccc}
\hline & Barberton $^{\mathrm{a}}$ & Belingwe $^{\mathrm{b}}$ & Commondale $^{\mathrm{c}}$ & Synthetic $^{\circ}$ \\
\hline $\mathrm{SiO}_{2}$ & 49.1 & 48.0 & 46.7 & 51.90 \\
$\mathrm{TiO}_{2}$ & 0.41 & 0.34 & 0.07 & 0.40 \\
$\mathrm{Al}_{2} \mathrm{O}_{3}$ & 4.65 & 7.0 & 5.14 & 8.30 \\
$\mathrm{Cr}_{2} \mathrm{O}_{3}$ & 0.37 & 0.23 & 0.44 & 0.56 \\
$\mathrm{FeO}$ & 11.4 & 11.0 & 7.48 & 0.03 \\
(total $)$ & & & & \\
$\mathrm{MnO}$ & 0.20 & 0.20 & 0.13 & 0.07 \\
$\mathrm{MgO}$ & 23.2 & 25.7 & 36.62 & 27.77 \\
$\mathrm{CaO}$ & 10.2 & 7.0 & 3.12 & 10.34 \\
$\mathrm{~K}_{2} \mathrm{O}$ & 0.03 & 0.072 & 0.00 & 0.002 \\
$\mathrm{Na} 2 \mathrm{O}$ & 0.28 & 1.25 & 0.34 & 0.60 \\
$\mathrm{P}_{2} \mathrm{O}_{5}$ & - & 0.033 & 0.00 & 0.11 \\
$\mathrm{NiO}_{\mathrm{Total}}$ & 0.16 & 0.065 & 0.20 & 100.08 \\
\hline
\end{tabular}

a From Parman et al. (1997).

b From Shimizu et al. (2005).

c From Wilson (2003).

a better analog, a "synthetic komatiite" displaying orthopyroxene spinifex was created by slowly cooling in an elongated graphite capsule a bulk composition based on XRS measurements taken at flare \#5, as described in Nittler et al. (2011). The $\mathrm{fO}_{2}$ of the experiment was buffered by the graphite capsule at an $\mathrm{fO}_{2}$ of $\sim 2 \mathrm{log}$ units below the iron-wustite buffer. Thus nearly all of the Fe was present as Fe metal and the silicate was nearly Fe-free, as would be expected for any Mercury lava.

In Table 1 the major elemental composition for the 3 natural samples and the synthetic sample are given. We handle our natural komatiite samples following our standard procedures: we crush the bulk rocks into smaller particles, then sieve them to the four PEL standard particle size ranges $(<25 \mu \mathrm{m}, 25-63 \mu \mathrm{m}$, $63-125 \mu \mathrm{m}, 125-250 \mu \mathrm{m})$. For the synthetic sample only $0.3 \mathrm{~g}$ were available, so we decided to gently grind it by hand to obtain fine dust, directly comparable with the $<25 \mu \mathrm{m}$ grain size we got for the other samples.

\subsection{Planetary emissivity laboratory}

During the last 10 years the Planetary Emissivity Laboratory (PEL) has been operating in various configurations to provide emissivity, reflectance, and transmission spectra of silicate rocks and minerals to be used for the study of planetary and minor bodies surfaces (e.g. Maturilli et al., 2006, 2008; Helbert and Maturilli, 2009; Sprague et al., 2009; Vernazza et al., 2010; Helbert et al., 2013a, 2013b).

At PEL we operate two Bruker Fourier transform infrared (FTIR) spectrometers, both equipped with their external chamber for emissivity measurements. To maximize the signal throughput no optical windows are placed between the spectrometers and their external chambers. A purge gas generator provides $\mathrm{CO}_{2}, \mathrm{H}_{2} \mathrm{O}$ and dust free purge air for the chambers and to drive the air-bearings for the mirrors of both spectrometers.

The spectrometer Bruker IFS 88 operates completely under purged air: biconical reflectance and transmittance measurements of samples in dry air can be obtained in the extended wavelength range from 0.4 to $16 \mu \mathrm{m}$, emissivity can be measured for sample surface temperature from $20^{\circ} \mathrm{C}$ to approx. $150{ }^{\circ} \mathrm{C}$ in the $1.4-16 \mu \mathrm{m}$ spectral range.

The second spectrometer, a Bruker Vertex $80 \mathrm{~V}$ allows measuring the bidirectional reflectance and transmittance of samples in the whole $1-100 \mu \mathrm{m}$ wavelength range.

The high-temperature chamber attached to the Vertex $80 \mathrm{~V}$ allows heating (via induction system) the samples to temperatures up to $1000 \mathrm{~K}$ under vacuum conditions (medium vac- 

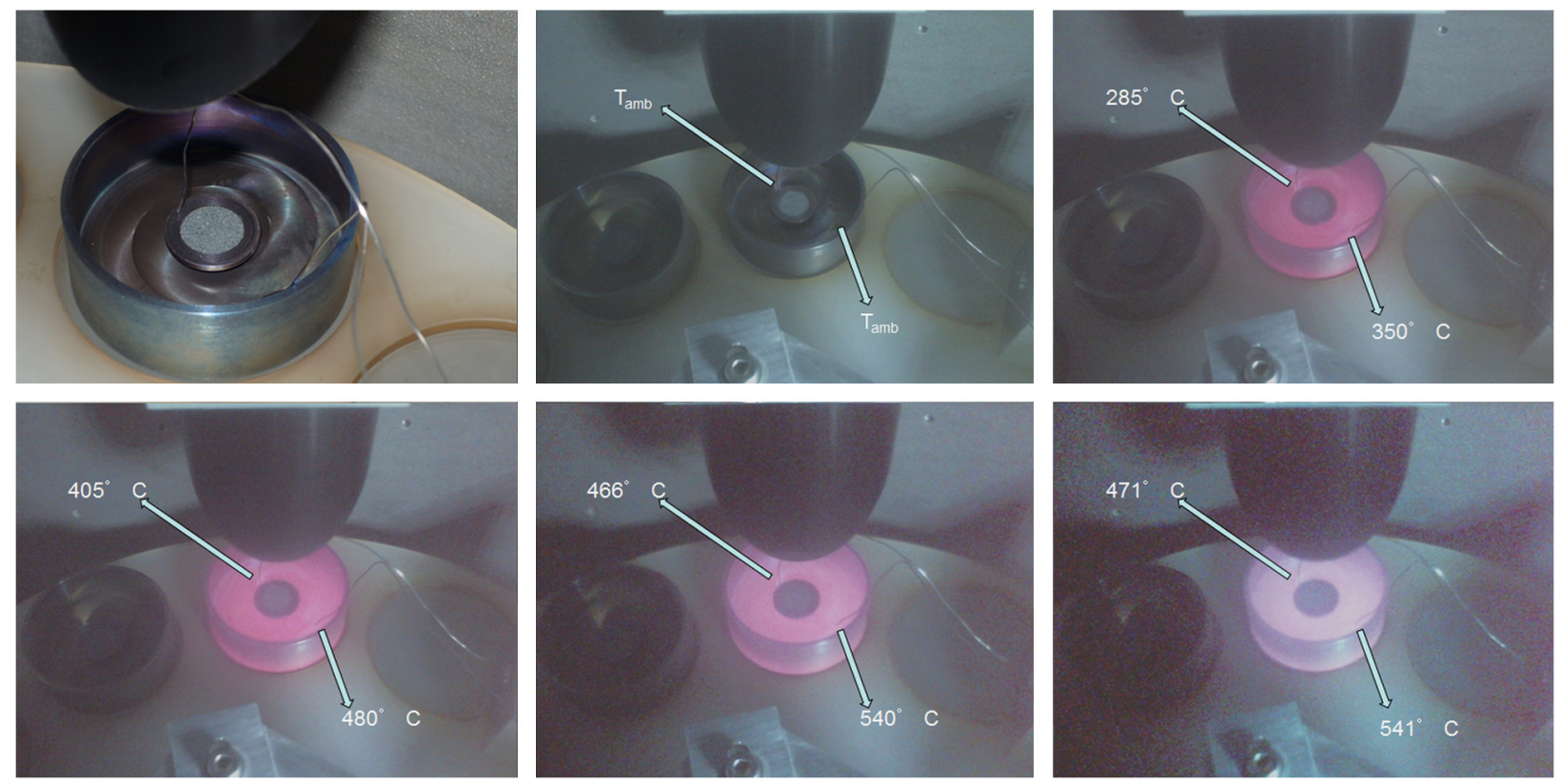

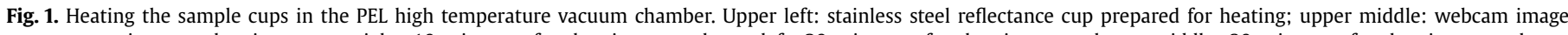

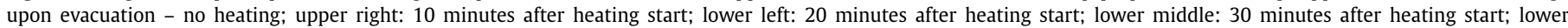
right: 45 minutes after heating start.

uum - 10-100 Pa). Details on the PEL set-up and its performance are discussed in Helbert and Maturilli (2009), Helbert et al. (2013a, 2013b).

\section{Procedure}

For the study we present here we follow our typical three step procedure. At first, reflectance of fresh samples is measured. Then the samples are thermally processed at Mercury daytime temperatures under vacuum conditions in the PEL planetary simulation chamber. Finally reflectance measurements are obtained for all thermally processed samples. Reflectance spectra measured before and after the thermal processing are compared to assess the permanent spectral changes originating by the exposure to temperatures typical of Mercury daytime.

In the following section we provide further details on the experimental procedures we used to thermally process our komatiitic samples.

\subsection{Reflectance measurements of fresh materials}

As a standard procedure at PEL, we keep our samples stored in a desiccator and we remove them just before the measurements. The samples are filled in stainless steel sample cups for reflectance measurements. The visible and infrared biconical reflectance spectra for all the samples are measured at room temperature in a purged environment with the Bruker IFS 88 instrument and the Harrick Seagull ${ }^{\mathrm{TM}}$ variable-angle reflection accessory. The visible spectral range (VIS, $0.45-1.1 \mu \mathrm{m}$ ) is sampled with a Si-diode detector and a quartz beamsplitter. For the mid-infrared range (MIR, 1.4-16 $\mu \mathrm{m}$ ), a nitrogen-cooled MCT detector and a KBr beamsplitter are used. We chose illumination angles $i=e=40^{\circ}$ to agree with the majority of the observations from the MESSENGER Mercury Atmospheric and Surface Composition Spectrometer (MASCS). We follow PEL standard protocols for the reflectance measurements including a careful alignment of the variable-angle reflection accessory before each set of measurements. A Halon disc is used as reflection standard in the VIS spectral range, while a goldplated sandpaper is the MIR standard we used. For each spectrum 500 scans are recorded and averaged to increase the signal to noise ratio of the data.

\subsection{Thermal processing}

The small stainless steel cups used for reflectance measurements containing the samples are placed in the high temperature emissivity chamber. They are placed in larger stainless steel cups, normally used for emissivity measurements in the PEL set-up, as shown in Fig. 1. The sample cups are then placed on the rotating carousel in the chamber. Each sample cup is equipped with 2 type K-thermopiles as temperature sensors, one reading the sample cup temperature, the other reading the temperature at the bottom of the large steel cup (see Fig. 1). In this way, we have a reading of the sample temperature as well as of the thermal environment of the samples. The chamber is closed and slowly evacuated: the rate of the evacuation is controlled with a manually operated valve to ensure that gas drag does not distribute material in the chamber. The samples are kept cold for $1 \mathrm{~h}$ in vacuum to get rid of air trapped in the sample, with pressure stabilized at approximately $10 \mathrm{~Pa}$.

The sample reaches within $45 \mathrm{~min}$ a temperature of $500^{\circ} \mathrm{C}$ as measured by the temperature sensor on the sample cup, and is kept at this temperature for $30 \mathrm{~min}$. We decided to heat up 2 samples for working day: having a total of 13 samples ( 3 komatiites in 4 grain sizes +1 synthetic) this already makes 7 days only for heating the samples. Wanting to reduce the period of thermally processing the samples as much as possible, to avoid that a long waiting time could "cure" the spectral changes we induced on the samples, we chose the $30 \mathrm{~min}$ heating time, since we noticed in previous experiments (see Maturilli et al., 2012) that already this amount of time is enough for the samples to show significant spectral changes induced from the thermal processing. However, as can be seen from Fig. 1, each sample underwent already temperatures higher that $400^{\circ} \mathrm{C}$ just $15 \mathrm{~min}$ after starting to heat, that brings the thermal processing time above $400^{\circ} \mathrm{C}$ to at least one hour. The sample is monitored with the webcam in the chamber over the whole heating period. Fig. 1 shows consecutive images of a sample cup obtained with the camera system in the chamber while the sample was heated up. Proceeding from upper to lower panel and from left to right, the image is more and more blurred by the deformation of the camera lens and increased CCD thermal noise due to the radiated heat. 
After the end of the 30 min peak temperature period the sample carousel is turned to the next position. As soon as the hot sample is moved out of the range of the induction system it starts to slowly cool radiatively.

The same heating procedure is repeated for all samples. After the last sample is exposed to Mercury dayside temperatures for $30 \mathrm{~min}$ the induction system is deactivated. After a waiting period of $1 \mathrm{~h}$ to allow the last sample to reach room temperature as witnessed by the temperature sensors the chamber is vented again slowly. After the chamber has reached ambient pressure the access hatch is opened.

\subsection{Reflectance measurements of the thermally processed samples}

The samples are placed again in the IFS 88 purged sample compartment for reflectance measurements following the same procedure as the initial measurements before thermal processing. After the spectral measurements the thermally processed samples are stored again in a desiccator.

\section{Discussion}

The reflectances of all samples are measured in the VIS and MIR spectral ranges directly before and after thermal processing. This allows us to analyze the spectral change induced by exposing the samples to peak Mercury surface temperatures. The purging time before the spectral measurement was reduced to only a few minutes, in order to measure the samples as quickly as possible after the thermal processing. This non perfect purging of the sample chamber results in some clearly indentifiable atmospheric features present in the MIR reflectance spectra that do not affect the overall spectral characteristics.

In Fig. 2 the VIS and MIR spectra (fresh and after $T$ processing) for the 4 PEL separates of the Barberton sample are shown. In the visible spectral range (Fig. 2A-B), the observed spectral changes (reddening) between fresh and $T$ processed samples depend on the grain size, with greater changes occurring for the finer samples (more Mercury relevant particles). In the near and mid-infrared spectral range (Fig. 2C) the variations between fresh and $T$ processed measurements show less dependence from the particle size, although the difference between the finer and the coarser grain size fraction is still remarkable, but it seems to be confined to the regions between 1.4 and $5 \mu \mathrm{m}$ (where the $\mathrm{O}-\mathrm{H}$ bond shows stretching features), and between 8 and $12 \mu \mathrm{m}$, where the reststrahlen bands occur. The small band centred at $4.3 \mu$ is a $\mathrm{CO}_{2}$ adsorption band, originating from a non perfect purging, as mentioned before. It is important to note that the spectral changes after heating the samples have an effect on the general slope in the VIS spectral range.

Fig. 3 shows the VIS and MIR spectra for fresh and thermally processed samples in the 4 typical PEL particle size ranges for the Belingwe komatiitic sample. The spectral changes (Fig. 3A-B) in the finest grain size fraction are comparable to those observed for the Barberton sample, and they are much more evident than for all the other 3 particle size ranges, where the difference between fresh and thermally processed samples seems to be a quasi-constant contribution. Spectral changes in the MIR (Fig. 3C) between fresh and heated samples have a higher influence for the smaller particle sizes, and tend to disappear when increasing the grain size dimensions, being nearly negligible for the $125-250 \mu \mathrm{m}$ particle size range.

For the Commondale sample (Fig. 4), the spectral changes after heating the samples in vacuum at Mercury peak dayside temperature do not seem to follow the trend with grain sizes, although they remain larger for the smaller particle separate. In the MIR

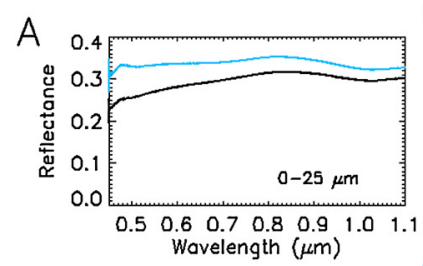

Borberton
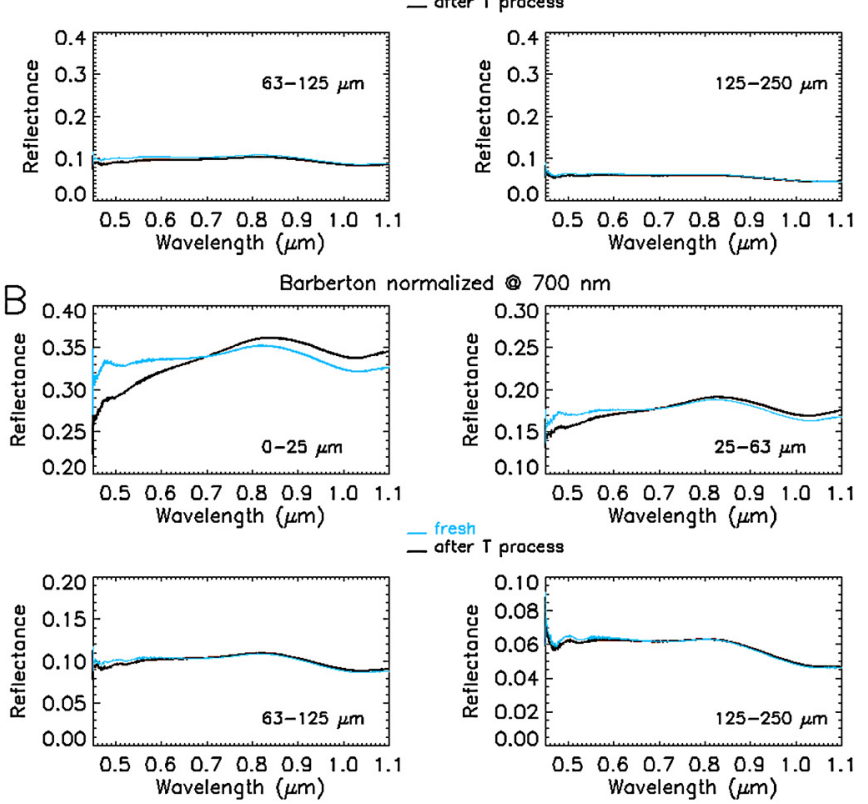

Z ofter $T$ process

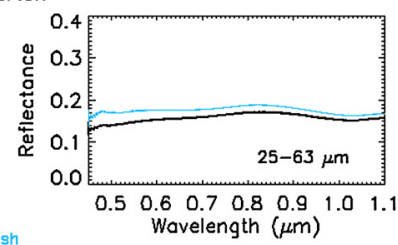

process

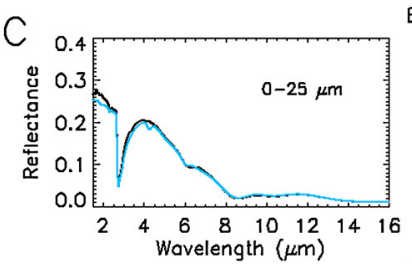

Barberton
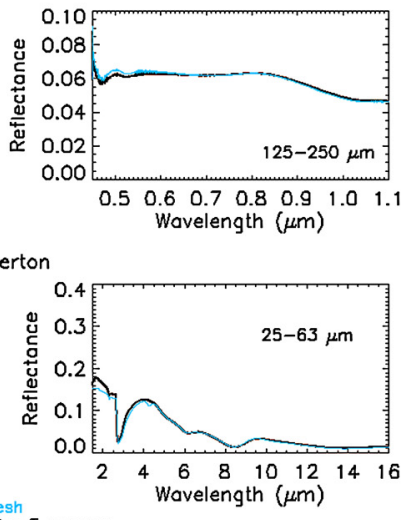

Z ofter $T$ process
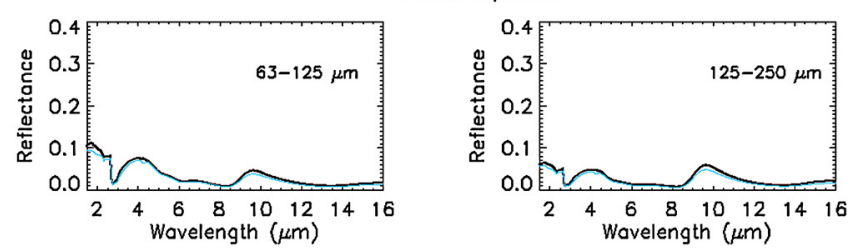

Fig. 2. Visible (panel A is absolute reflectance, B is reflectance normalized at $700 \mathrm{~nm}$ ) and infrared (C panel) biconical reflectance spectra $\left(i=e=40^{\circ}\right)$ of the Barberton komatiite in the four PEL grain size fractions.

spectral range very little changes are observed, mainly for the smaller separates and only in the region below $5 \mu \mathrm{m}$.

In the case of synthetic komatiite (Fig. 5), substantial spectral changes are visible in both channels. Darkening and reddening are similar to those already observed for the natural komatiite samples, even though this synthetic sample is much brighter with respect to the natural komatiites.

In Fig. 6 we show all the reflectance measurements for fresh and thermally processed samples converted to emissivity ( $E=$ $1-R)$ in the MERTIS spectral range. The spectra in the TIR present many more diagnostic features as in the VIS range, making the interpretation of mercurian emission spectra easier for the instrument on board the ESA BepiColombo mission.

In summary all sample exhibit a general darkening and reddening of the visible and near infrared spectra after thermal processing. No other spectral changes are observed in this spectral 

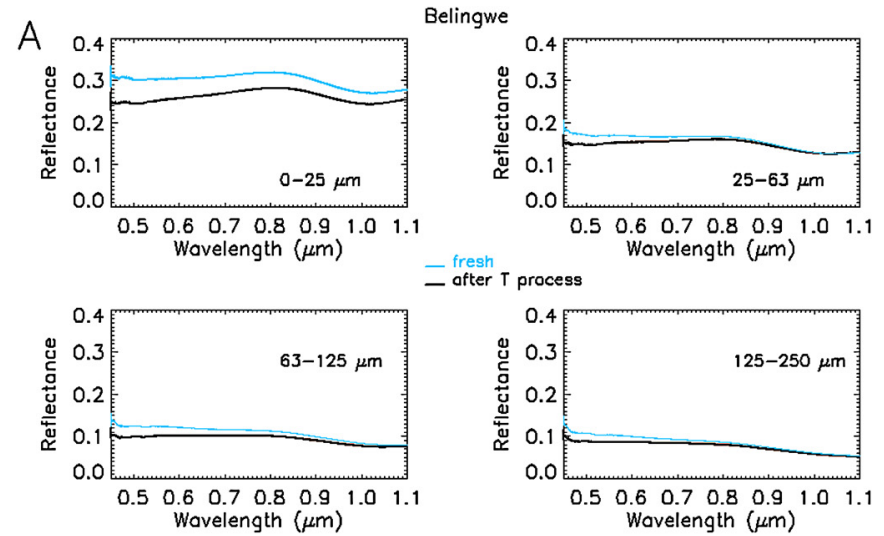

二 ofter

Wovelength $(\mu \mathrm{m})$

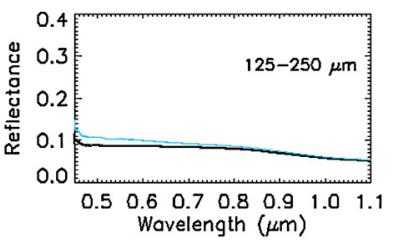

Belingwe normalized $700 \mathrm{~nm}$
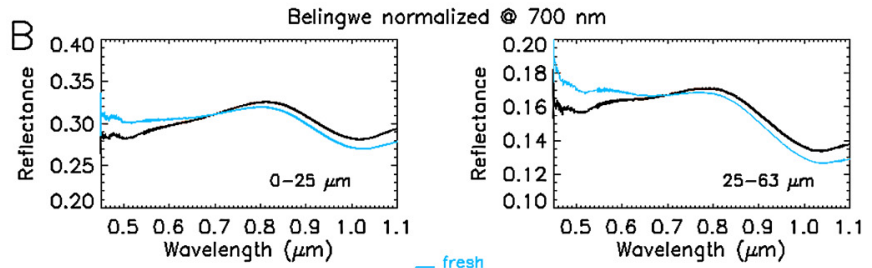
- fresh Wovelength $(\mu \mathrm{m})$
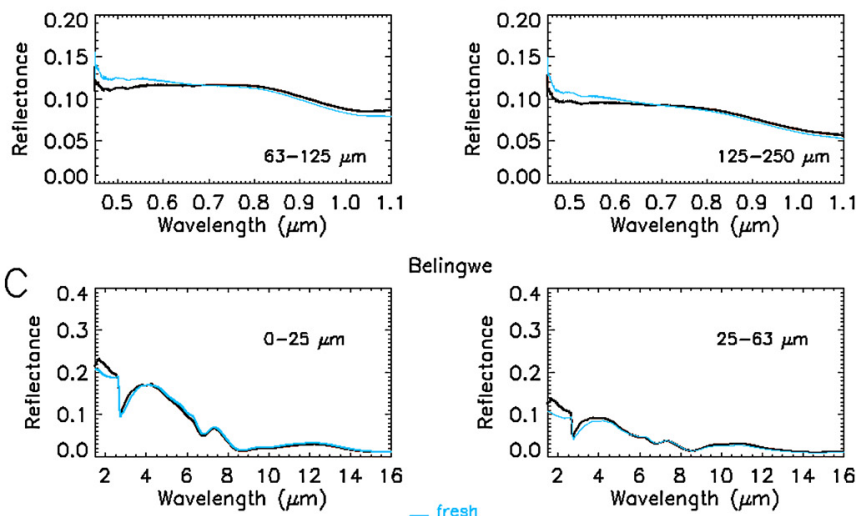

Belingwe

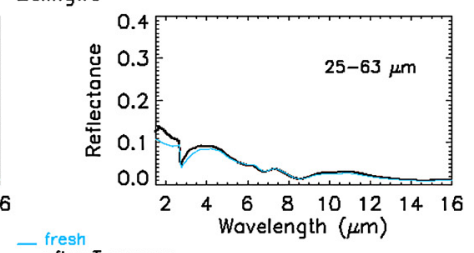

二 ofter $T$ process
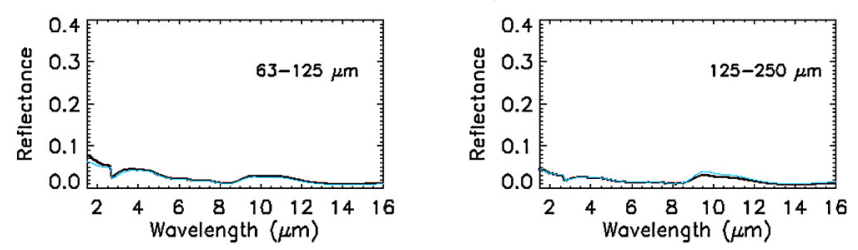

Fig. 3. Visible (panel A is absolute reflectance, $B$ is reflectance normalized at $700 \mathrm{~nm}$ ) and infrared (C panel) biconical reflectance spectra $\left(i=e=40^{\circ}\right)$ of the Belingwe komatiite in the four PEL grain size fractions.

range, in particular we do not see the formation or loss of spectral bands. Darkening and reddening effects are usually associated to three physical effects happening to the heated materials: oxidation, dehydration of the water-bearing phases and destruction or shifting of colour centres (Nassau, 1984). XRD analysis of fresh and heated materials can help us to understand which physical process we induced in the materials we heated in vacuum at temperatures higher than $400^{\circ} \mathrm{C}$ in our experiment. Nevertheless, in all the spectra of heated komatiites we see no indication of a spectral feature at $1 \mu \mathrm{m}$ that could take into account of oxidation in the samples.

Table 2 shows the results of a powder XRD analysis performed at the GFZ of Potsdam. For each komatiite sample, we analyzed the smaller available grain size range $(<25 \mu \mathrm{m})$. We handpicked a $50 \mathrm{mg}$ sample from the fresh material, and from the materials after thermal processing in vacuum at $500^{\circ} \mathrm{C}$. For each sample $1 \mathrm{mg}$ was ground in an agate mortar for several minutes, diluted with Elmer's White glue and evenly spread on a "zero scattering"

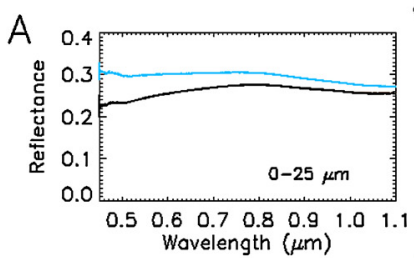

Commondale
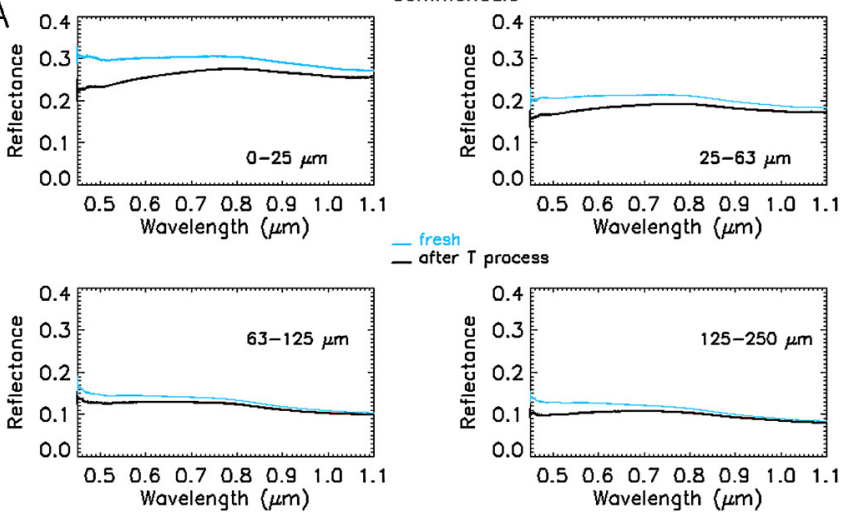

— fresh $\mathrm{ofter} T$ process

Commondale normalized @ $700 \mathrm{~nm}$
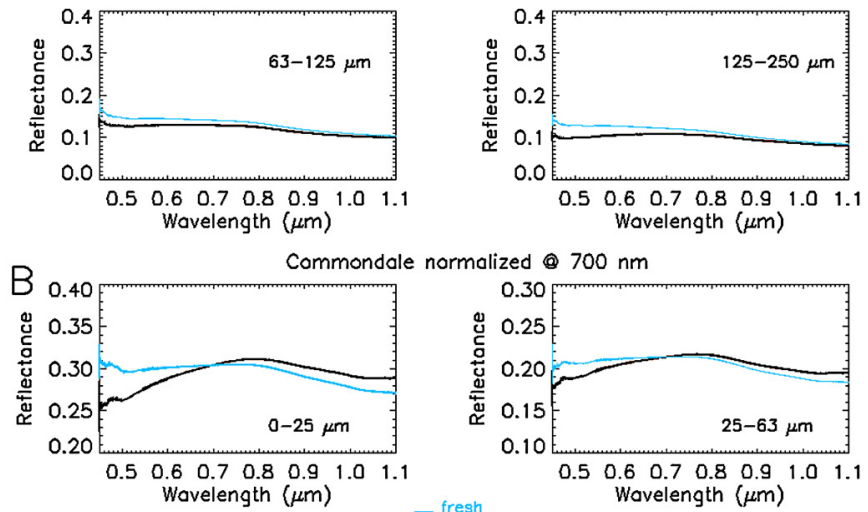

二 ofter

Wavelength $(\mu \mathrm{m})$
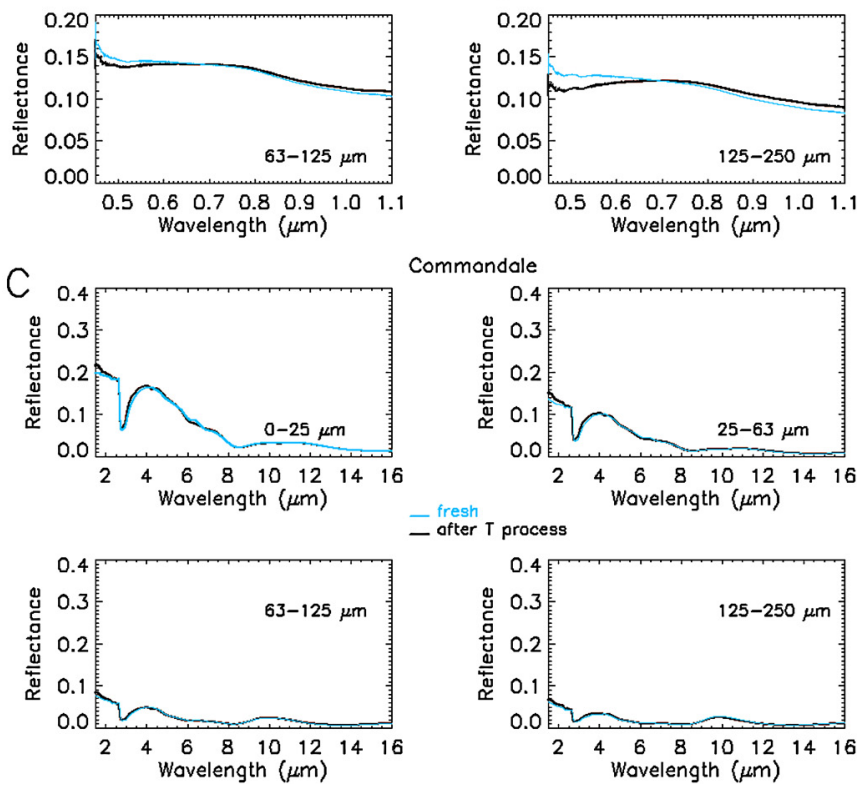

Fig. 4. Visible (panel $A$ is absolute reflectance, $B$ is reflectance normalized a $700 \mathrm{~nm}$ ) and infrared (C panel) biconical reflectance spectra $\left(i=e=40^{\circ}\right)$ of the Commondale komatiite in the four PEL grain size fractions.

circular, clear, acetate foil. To minimize preferential orientation, the powder was stirred during drying. The foil was covered by a second clean foil and then placed into the transmission sample holder. Powder XRD patterns were recorded in transmission using a fully automated STOE STADI P diffractometer (CuK $\alpha 1$ radiation), equipped with a primary monochromator and a $7^{\circ}$-wide position sensitive detector (PSD). The normal-focus Cu X-ray tube was operated at $40 \mathrm{kV}$ and $40 \mathrm{~mA}$, using a take-off angle of $6^{\circ}$. Intensities were recorded in the range from 5 to $125^{\circ} 2 \Theta$ with a detector step size of $0.1^{\circ}$ and a resolution of $0.01^{\circ}$. Counting times were selected to yield a maximum intensity of 4000-5000 counts for each sample resulting in 5-20 s per detector step.

For all samples the measured major primary and secondary mineralogy is in agreement with the reference papers listed in Table 1 . The XRD results have an uncertainty of $\pm 0.5 \%$ therefore we can only consider changes between the fresh and the thermally processed sample of more than $2-3 \%$ as significant. 

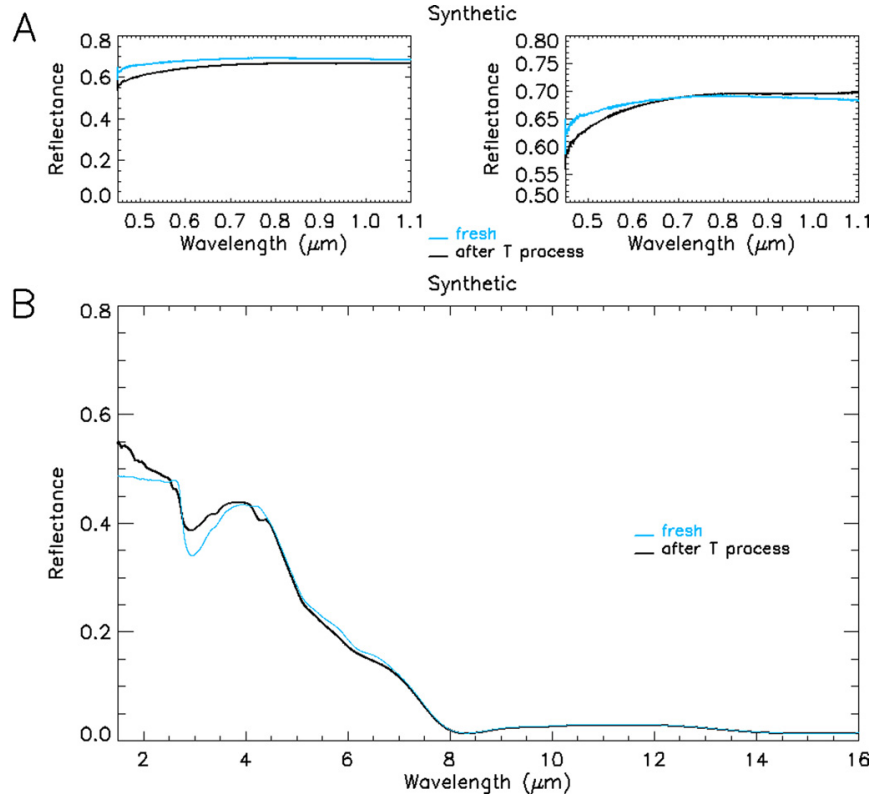

Fig. 5. Visible (A panel, left is absolute reflectance, right is reflectance normalized at $700 \mathrm{~nm}$ ) and infrared (B panel) biconical reflectance spectra $\left(i=e=40^{\circ}\right)$ of the Brown University synthetic komatiite (fine dust).

The heated Barberton sample seems to show a significant enrichment of clinopyroxene and phyllosilicate serpentine, and at the same time a loss of amphibole. On the other hand, the content of chlorite is invariant. We interpret this seemingly contradicting results as an indication for a large variation of the content of altered material in the Barberton sample rather than actually changes related to the thermal processing.

In the case of the Belingwe sample, no substantial changes occur between sample 1141 and the corresponding heated sample 1161 , and the same is true for the Commondale sample, where no structural changes can be observed between the fresh 1146 sample and the heated one, labelled 1166 . We see neither indications for significant dehydration of the altered phases, nor do we see indications for significant oxidation.

The synthetic sample labelled 1151 shows after thermal processing a slight enrichment of orthopyroxenes at the expense of metastable clinopyroxenes. This could be an indication that, though synthesis implied a slow cooling rate (that should avoid the formation of metastable minerals), some of the phases synthetized did not reach a final crystallization structure and could be modified due to the energy they received when heated at $500^{\circ} \mathrm{C}$ in vacuum. However, based on the XRD results we cannot see evidence that oxidation of the synthetic sample (that was produced under very low oxygen fugacity) occurred during thermal processing at Mercury conditions in the PEL chamber.

Sample dehydration can also be detected spectrally by a change in the bands in the 2-3 micron range. As can be seen from comparing Figs. 2B, 3B, 4B and 5A the only spectrum showing a significant change in this range is actually the synthetic sample. If we assume that this sample cannot be significantly dehydrated, all other samples show even less effect, meaning that dehydration is not the main contributing factor to the spectral changes we observe.

The fact that smaller grain sizes are more strongly affected than larger might be related to the efficacy of the heating. Small grain sizes will reach a higher temperature through the whole grain, while larger grains will have a temperature gradient towards the centre.

Having excluded oxidation and dehydration from the list of possible causes for the darkening and reddening we observe in the visible spectra, we can deduce that shifting of colour centres in
Table 2

Results (expressed in weight \%) of powder XRD analysis on all the samples ( $<25 \mu \mathrm{m}$ fraction if available), before and after thermal processing. Minimum error $\pm 0.5 \%$.

\begin{tabular}{|c|c|c|c|}
\hline Barberton & & $\begin{array}{l}00000801 \\
\text { fresh sample }\end{array}$ & $\begin{array}{l}00001156 \\
\text { vacuum heated }\end{array}$ \\
\hline & Forsterite & 8.2 & 9.3 \\
\hline & Mg-rich clinopyroxene & 23.7 & 27.9 \\
\hline & Ca-rich plagioclase & 3.8 & 1.5 \\
\hline & Tremolite & 16.2 & 10.7 \\
\hline & Clinochlore & 27.5 & 25.0 \\
\hline & Chrysotile & 10.8 & 21.1 \\
\hline & Clinozoisite & 4.3 & 2.0 \\
\hline & Chromite & 0.9 & 0.6 \\
\hline & Magnetite & 4.6 & 1.8 \\
\hline \multirow[t]{10}{*}{ Belingwe } & & $\begin{array}{l}00001141 \\
\text { fresh sample }\end{array}$ & $\begin{array}{l}00001161 \\
\text { vacuum heated }\end{array}$ \\
\hline & Forsterite & 32.6 & 33.7 \\
\hline & Mg-rich clinopyroxene & 28.7 & 28.9 \\
\hline & Clinoenstatite & 0.2 & 0.1 \\
\hline & Mg-rich orthopyroxene & 3.1 & 2.5 \\
\hline & Ca-rich plagioclase & 15.9 & 17.5 \\
\hline & Chrysotile & 7.0 & 5.3 \\
\hline & Talc & 11.4 & 11.2 \\
\hline & Chromite & & \\
\hline & Magnetite & 0.4 & 0.2 \\
\hline \multirow[t]{10}{*}{ Commondale } & & $\begin{array}{l}00001146 \\
\text { fresh sample }\end{array}$ & $\begin{array}{l}00001166 \\
\text { vacuum heated }\end{array}$ \\
\hline & Forsterite & 17.9 & 19.9 \\
\hline & Mg-rich clinopyroxene & 0.8 & 2.1 \\
\hline & Mg-rich orthopyroxene & 13.5 & 12.6 \\
\hline & Ca-rich plagioclase & 2.7 & 2.8 \\
\hline & Clinochlore & 20.3 & 19.4 \\
\hline & Chrysotile & 4.5 & 5.2 \\
\hline & Tremolite & 29.5 & 29.2 \\
\hline & Talc & 9.9 & 8.1 \\
\hline & Magnetite & 1.0 & 0.8 \\
\hline \multirow[t]{5}{*}{ Synthetic } & & $\begin{array}{l}00001151 \\
\text { fresh sample }\end{array}$ & $\begin{array}{l}00001171 \\
\text { vacuum heated }\end{array}$ \\
\hline & Forsterite & 28.1 & 25.8 \\
\hline & Mg-rich clinopyroxene & 1.7 & 3.6 \\
\hline & Clinoenstatite & 67.9 & 62.0 \\
\hline & Mg-rich orthopyroxene & 2.2 & 8.6 \\
\hline
\end{tabular}

the crystal structures is the most likely physical explanation for the observed spectral changes. In diamonds, for example, the colour is influenced by defects or impurities such as nitrogen, boron or a lattice vacancy. In diamond, nitrogen atoms are present either in an aggregated form of nitrogen, or in a group of four nitrogen atoms surrounding a vacancy. The effect of the heating is to knock some of the carbon atoms away from their normal lattice sites leaving a vacancy. The displaced carbon atoms become interstitial occupying space between carbon atoms. The electronic transition of vacancies gives rise to green or blue green in the diamond, while the interstitial carbon is optically inactive. A vacancy can be also trapped at a colour centre to produce a shift in those centres, whose electronic transition can give rise to yellow, orange or brown colour, where the end result depends on the initial colour of the diamond before irradiation and the time taken for irradiation and annealing.

We propose that the thermal processing of our komatiite samples anneals structural faults that trap colour centre resulting in the spectral changes we observe. Unfortunately there is no simple analytical technique available to directly measure the destruction of colour centres in complex materials containing many different phase like our komatiite samples (Nassau, 1978).

\section{Summary}

At the Planetary Emissivity Laboratory (PEL) of the German Aerospace Center (DLR) we are working on the spectral characterization (in the VIS and TIR spectral ranges) of Mercury analog 

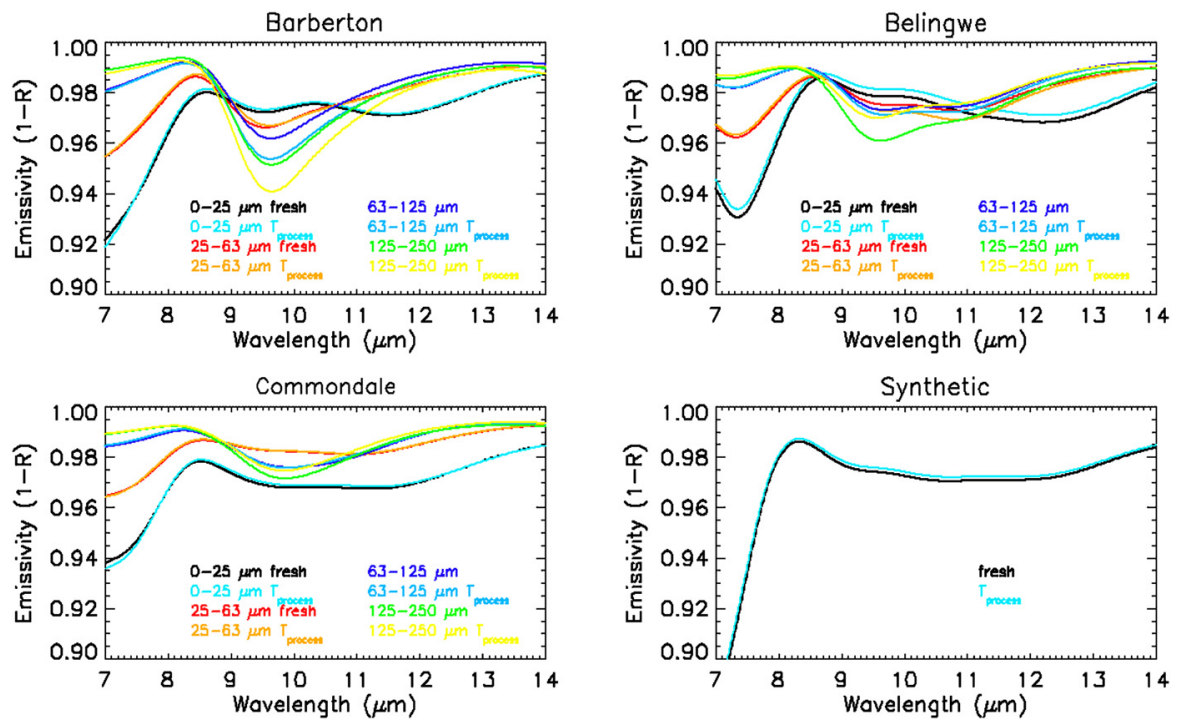

Fig. 6. All of the komatiites, fresh and after thermal processing, converted in emissivity $(E=1-R)$ in the MERTIS spectral range.

materials. After already publishing the results on sulfides as hollows forming materials (Helbert et al., 2013a), as the second step we concentrated on komatiites, possible analogs for Mercury regions with $\mathrm{Mg} / \mathrm{Si}>0.8$. Future step include the spectral characterization of other mercurian analogues, such like orthopyroxene + alkali feldspar mixtures, low-Fe enstatitic chondrites, boninites, and others, to span the whole $\mathrm{Mg} / \mathrm{Si}$ range of values for Mercury.

We have measured visible and infrared reflectance spectra for a suite of natural and synthetic komatiite samples, before and after heating in vacuum to $500^{\circ} \mathrm{C}$, with illumination angles matching the majority of the MASCS observations. Samples after thermal processing show changes in both the VIS and MIR, while XRD analysis show no substantial changes in the primary and secondary mineral phases and no indication for significant oxidation. Changes in the VIS are stronger than the changes observed in the MIR, with reddening occurring for all samples. Most samples darkened, though iron content of the sample is not the main driver for darkening, as shown from the iron-free synthetic komatiite. The amount and type of spectral change seems to be a complex function of (at least) temperature, grain size and sample composition. Therefore it is currently not possible to predict a-priori the effects of heating on a sample, requiring extensive laboratory efforts to characterize the changes. Previous experiments on repeated heating and cooling of komatiites show that the spectral changes from thermal processing are cumulative (Maturilli et al., 2012). Based on the results of the XRD analysis we can exclude oxidation or dehydration of the samples as the main cause for the observed spectral changes. We propose the destruction of colour centres during the thermal processing as a probable main cause. The samples receive sufficient thermal energy to anneal structural defects and thereby destroy the colour centres. This process is well established in the gem industry where it is routinely used to change the colour of gem stones (Nassau, 1984).

The spectra presented here show that it is very challenging to distinguish compositionally distinct komatiites based solely on the visible and near infrared spectral range. This implies that neither the MDIS nor the MASCS instrument on MESSENGER would be able to identify a certain type of komatiite. Only in combination with compositional data provided by the XRS the MESSENGER mission might be able to identify the presence of komatiites on Mercury's surface. This is limited to the spatial resolution of the XRS instrument of a few $100 \mathrm{~km}$.

The upcoming ESA BepiColombo mission (Benkhoff et al., 2010) will be able to build on the MESSENGER results. Based on the spec- tra presented here the MErcury Radiometer and Thermal infrared Imaging Spectrometer (MERTIS) instrument (Hiesinger and Helbert, 2010; Helbert et al., 2010) has the capability to map different types of komatiites based on their different spectral characteristics in the spectral range between 7 and $14 \mu \mathrm{m}$ on a spatial scale of $500 \mathrm{~m}$. This will be supported by the telescope channel of the Mercury Imaging X-ray Spectrometer (MIXS) that provides compositional data on a spatial scale of a few $\mathrm{kms}$.

\section{References}

Benkhoff, J., van Casteren, J., Hayakawa, H., Fujimoto, M., Laakso, H., Novara, M. Ferri, P., Middleton, H.R., Ziethe, R., 2010. BepiColombo-Comprehensive exploration of Mercury: mission overview and science goals. Planet. Space Sci. 58 (1-2), 2-20. http://dx.doi.org/10.1016/j.pss.2009.09.020.

Charlier, B., Grove, T.L., Zuber, M.T., 2013. Phase equilibria of ultramafic compositions on Mercury and the origin of the compositional dichotomy. Earth Planet. Sci. Lett. 363, 50-60. http://dx.doi.org/10.1016/j.epsl.2012.12.021.

Evans, L.G., Peplowski, P.N., Rhodes, E.A., Lawrence, D.J., McCoy, T.J., Nittler, L.R., Solomon, S.C., Sprague, A.L., Stockstill-Cahill, K.R., Starr, R.D., Weider, S.Z., Boynton, W.V., Hamara, D.K., Goldsten, J.O., 2012. Major-element abundances on the surface of Mercury: results from the MESSENGER gamma-ray spectrometer. J. Geophys. Res. 117, E00L07. http://dx.doi.org/10.1029/2012JE004178.

Helbert, J., Hiesinger, H., Walter, I., Sauberlich, T., Maturilli, A., D’Amore, M., Knollenberg, J., Lorenz, E., Peter, G., Arnold, G., 2010. MERTIS: understanding Mercury's surface composition from mid-infrared spectroscopy. Proc. SPIE 7808, 78080J. http://dx.doi.org/10.1117/12.859816.

Helbert, J., Maturilli, A., 2009. The emissivity of a fine-grained labradorite sample at typical Mercury dayside temperatures. Earth Planet. Sci. Lett. 285 (3-4), 347-354. http://dx.doi.org/10.1016/j.epsl.2009.02.031.

Helbert, J., Maturilli, A., D’Amore, M., 2013a. Visible and near-infrared reflectance spectra of thermally processed synthetic sulfides as a potential analog for the hollow forming materials on Mercury. Earth Planet. Sci. Lett. 369-370, 233-238. http://dx.doi.org/10.1016/j.epsl.2013.03.045.

Helbert, J., Nestola, F., Ferrari, S., Maturilli, A., et al., 2013b. Olivine thermal emissivity under extreme temperature ranges: implication for Mercury surface. Earth Planet. Sci. Lett. 371, 252-257. http://dx.doi.org/10.1016/j.epsl.2013.03.038.

Hiesinger, H., Helbert, J., MERTIS Co-I Team, 2010. The Mercury radiometer and thermal infrared spectrometer (MERTIS) for the BepiColombo mission. Planet. Space Sci. 58 (1-2), 144-165. http://dx.doi.org/10.1016/j.pss.2008.09.019.

Maturilli, A., Helbert, J., Moroz, L., 2008. The Berlin emissivity database (BED) Planet. Space Sci. 56, 420-425.

Maturilli, A., Helbert, J., St. John, J., D’Amore, M., Head, J.W., Vaughan, W.M., 2012 Visible-infrared reflectance and emissivity spectra of a terrestrial komatiite as a guide to observations at Mercury. In: 43rd Lunar and Planetary Science Conference Abstracts. Abstract \#1394.

Maturilli, A., Helbert, J., Witzke, A., Arnold, G., Moroz, L., 2006. Emissivity measurements of analogue materials for the interpretation of data from PFS on Mars express and MERTIS on Bepi-Colombo. Planet. Space Sci. 54, 1057-1064.

Nassau, K., 1978. The origins of colour in minerals. Am. Mineral. 63, 219-229. 
Nassau, K., 1984. Gemstone enhancement: heat, irradiation, impregnation, dyeing and other treatments which alter the appearance of gemstones, and the detection of such treatments. Butterworths, ISBN 978-0408014472.

Nisbet, E.G., 1984. Komatiites. Eos 65 (37), 501-520.

Nisbet, E.G., Arndt, N.T., Bicke, M.J., Cameron, W.E., Chauvel, C., Cheadle, M., Hegner, E., Kyser, T.K., Martin, A., Renner, R., Roedder, E., 1987. Uniquely fresh 2.7 Ga komatiites from the Belingwe Greenstone-Belt, Zimbabwe. Geology 15 (12), 1147-1150.

Nittler, L.R., Starr, R.D., Wieder, S.Z., McCoy, T.J., Boynton, W.V., Ebel, D.S., Ernst, C.M., Evans, L.G., Goldsten, J.O., Hamara, D.K., Lawrence, D.J., McNutt Jr., R.L., Schlemm II, C.E., Solomon, S.C., Sprague, A.L., 2011. The major-element composition of Mercury's surface from MESSENGER X-ray spectrometry. Science 333 (6051), 1847-1850.

Nittler, L.R., Weider, S.Z., Starr, R.D., Crapster-Pregont, E.J., Ebel, D.S., Solomon, S.C., 2013. Mapping major element abundances on Mercury's surface with MESSENGER X-ray spectrometer data. In: 44th Lunar and Planetary Science Conference. Abstract \#2458.

Parman, S.W., Dann, J.C., Grove, T.L., de Wit, M.J., 1997. Emplacement conditions of komatiite magmas from the 3.49 Ga Komati formation, Barberton Greenstone Belt, South Africa. Earth Planet. Sci. Lett. 150 (3-4), 303-323.

Peplowski, P.N., Evans, L.G., Hauck II, S.A., McCoy, T.J., Boynton, W.V., Gillis-Davis, J.J., Ebel, D.S., Goldsten, J.O., Hamara, D.K., Lawrence, D.J., McNutt Jr., R.L., Nittler, L.R., Solomon, S.C., Rhodes, E.A., Sprague, A.L., Starr, R.D., Stockstill-Cahill, K.R. 2011. Radioactive elements on Mercury's surface from MESSENGER: implications for the planet's formation and evolution. Science 333 (6051), 1850-1852.

Peplowski, P.N., Lawrence, D.J., Rhodes, E.A., Sprague, A.L., McCoy, T.J., Denevi, B.W., Evans, L.G., Head, J.W., Nittler, L.R., Solomon, S.C., Stockstill-Cahill, K.R., Weider,
S.Z., 2012. Variations in the abundances of potassium and thorium on the surface of Mercury: results from the MESSENGER gamma-ray spectrometer. J. Geophys. Res. 117. http://dx.doi.org/10.1029/2012JE004141.

Shimizu, K., Nakamura, E., Maruyama, S., 2005. The geochemistry of ultramafic to mafic volcanics from the Belingwe Greenstone Belt, Zimbabwe: magmatism in an Archean Continental Large Igneous province. J. Petrol. 46 (11), 2367-2394. http://dx.doi.org/10.1093/petrology/egi059.

Sprague, A.L., Donaldson Hanna, K.L., Kozlowski, R.W.H., Helbert, J., Maturilli, A., Warell, J.B., Hora, J.L., 2009. Spectral emissivity measurements of Mercury's surface indicate Mg- and Ca-rich mineralogy, K-spar, Na-rich plagioclase, rutile, with possible perovskite, and garnet. Planet. Space Sci. 57 (3), 364-383.

Stockstill-Cahill, K.R., McCoy, T.J., Nittler, L.R., Hauck II, S.A., 2012. Magnesium-rich crustal compositions on Mercury: implications for magmatism from petrologic modeling. J. Geophys. Res. 117, E00L15. http://dx.doi.org/10.1029/2012JE004140.

Vernazza, P., Carry, B., Emery, J., Hora, J.L., Cruikshank, H., Binzel, R.P., Jackson, J., Helbert, J., Maturilli, A., 2010. Mid-infrared spectral variability for compositionally similar asteroids: implications for asteroid particle size distributions. Icarus 207 (2), 800-809.

Weider, S.Z., Nittler, L.R., Starr, R.D., McCoy, T.J., Cahill, K.S., Byrne, P.K., Denevi, B.W., Head, J.W., Solomon, S.C., 2012. Chemical heterogeneity on Mercury's surface revealed by the MESSENGER X-ray spectrometer. J. Geophys. Res. 117, E00L05. http://dx.doi.org/10.1029/2012JE004153.

Williams, D.A., Wilson, A.H., Greeley, R., 2000. A komatiites analog to potential ultramafic materials on Io. J. Geophys. Res. 105, 1671-1684.

Wilson, A.H., 2003. A new class of silica enriched, highly depleted komatiites in the southern Kaapvaal Craton, South Africa. Precambrian Res. 127, 125-141. 